\title{
How to Make Policy Research on Public Assets Management of Forest and Wildlife Sectors Successful?
}

\author{
Dr. Wenceslaus Mselya Sobayi \\ Faculty of Arts and Social Sciences, University of Nottingham, Malaysia Campus
}

\begin{abstract}
The situation of policy research in Tanzania and its contribution to the policy making, leaves much to be desired. The paper suggests that government investment in supply-driven research studies is of critical importance in order to know and understand fundamental issues and what really is taking place in forest and wildlife reserves as well as forest and wildlife management as a whole. There has been much preference for the use of stakeholders' recommendations as inputs into policy making process instead of using research studies. The stakeholders' recommendations have been used without subjecting them to validity test. A systematic validation test could help to double check the quality of issued stakeholders' recommendations. The practice in Tanzania of using stakeholders' recommendations as a direct policy input has contributed to weak policy provisions, and largely policy disjunctions. This is particularly prevalent in forest and wildlife management as there has been an increase in human-wildlife conflicts, deforestation, forest degradation, animal extinction and poaching. It is also evident that bureaucrats' way of handling research recommendations which differ from their own is amongst the bottlenecks of policy making in Tanzania, and this eventually undermines the value of policy research.
\end{abstract}

Keywords: Policy Research, Effective Policy, Forest and Wildlife Management, Tanzania

DOI: $10.7176 /$ PPAR/10-4-05

Publication date: April $30^{\text {th }} 2020$

\section{Introduction}

Policy research is a social scientific research which aims to solve an identified problem by applying the results of a particular research (Marshal 1998). It may also be used to evaluate a new or existing policy program, describe examples of best practice, measure social change, develop projections on the basis of large-scale modelling exercises, or consist of large-scale experimental research in real-life settings running for years and even decades (ibid).

The situation of policy research in Sub-Saharan Africa shows that most Governments tend to formulate policies without involving researchers in the process, bureaucrats are not ready to accept different views during the policy making process, and there is a massive suppression of new and different perspectives and opinions which differ with those of bureaucrats (Ajakaiye 2007 pp.20; 25). Thus, there is a need for policies to receive input from research and also to strengthen the capacity of research institutes while ensuring that both researchers and bureaucrats have good interactions (Young 2007). From a technical viewpoint, Ayuk and Marouani (2007) look at the entire policy management process as being driven by scientific research, and suggest that research institutions and individuals must ensure quality in their work and develop a communication strategy that make them attentive and responsive to the needs of bureaucrats.

The underlying reason for ensuring or maintaining quality as well as remaining attentive and responsive is due to the fact that, the link between policy research and policy making is non-linear (Ayuk and Marouani 2007). Additionally, Quattara et al (2007) suggest that, globalisation demands increasing complex and multi-disciplinary research, which most of the research institutes in Sub-Saharan Africa are not set up to handle, for that research institutes should design a new structure which will enable them to broaden their research programs in order to successfully feed into a wide range of policies.

The situation of policy research in Tanzania shows that policy making in Tanzania has been centrally managed by bureaucrats since the country's independence who had chosen a closed style of policy making which ensured that policy decisions were made in small and private cycles of elites and this practice later metamorphosed into an institutionalised political system (Tordoff 1972). In Tanzania, most of the government's policies are perceived as being formulated in the interest of the general public, therefore, makes it difficult to challenge them, as doing so would be interpreted as working against the public interest (Mattee 2007).

Policy making in Tanzania, is faced with a challenge of having a weak policy research environment, whereby policy research institutes encountered low financing, ineffective research, poor dissemination and low-level of utilisation of research findings and recommendations (ESRF 2004). During the reformation period of the 1980's until today, most African countries have been characterised as having weak research institutions which failed to assist in conducting impactful research to understand the actual needs of their country before formulating a particular policy (Dollar and Svensoon 2000).

In the 1980s and 1990s, several countries in Africa including Tanzania implemented Structural Adjustment Programs (SAPs) before conducting a thorough research into their actual social, economic and political needs and 
subsequently failed to bring about the expected positive results (Self 2011). Nonetheless, Tanzania like many African countries continue to depend on development partners' support both technical and financial (Hyden 2006). More often, policy making has been dependent on policy input from foreign consultants who do not have grounded knowledge of the issues involved which need to be addressed by the policy being formulated (Dollar and Svensoon 2000).

The situation has led to a dependency on development partners' requirements also described as imposed conditions and recommendations (Schlimmer and Provini 2015). In other words, Tanzania public policies are being formulated in response to the needs of development partners and not domestic needs which stemmed into failure of most public policies to address various social and economic challenges (Shivji 1986). A case in point, is the Forest Policy 1998 and Wildlife Policy 2007 (RE) which failed to address key policy issues such as HumanWildlife Conflicts (HWCs), deforestation, poaching and ever-decreasing livelihood outcomes of people residing around the forest and wildlife reserves (Lokina and Robinson 2008). Ndumbaro (1993) describes the country's adoption of liberalisation policies from the old central policy-making as the era of power shift in policy making from the state to development partners.

Babeiya (2011) argues that although development partners' influence in the new policy environment has continued to increase, there is no significant improvement due to most of the policies continue to be made without adequate information. However, development partners' support is significant and critical especially in managing forest and wildlife resources (Igoe and Croucher 2007).

Hence, the foregoing has necessitated the research question: how has change in quality of research results and recommendations as policy inputs, affected effectiveness of policy provisions that have been designed to improve forest and wildlife management in Tanzania?

\subsection{Study Objective}

To examine the way change in quality of research results and recommendations as policy inputs, has affected the effectiveness of policy provisions that have been designed to improve forest and wildlife management in Tanzania.

\subsection{Research Theories}

The theoretical framework underpinning this research lies in the guiding empirical theory of policy making propounded by Professor Robert E. Goodin. The Goodin theory postulates that sound and effective policies must be based on an analysis of the situation that is both empirically well-grounded and theoretically defensible (Goodin 1982 pp.7-9). The theory works by ensuing the underlying theoretical assumption that policies are made after understanding the social system through proper research, amongst others (ibid).

Additionally, Ayuk and Marouani theory postulates that effectiveness of policy provisions is directly affected by the quality of research outputs which feed into policy making (Ayuk and Marouani 2007). The theory works by ensuing the underlying theoretical assumption that African researchers and policy experts should be engaged in the policy making process as they have a better understanding of the social, economic and political environment in which they operate. Meanwhile, theory works by following the underlying theoretical principle that African research studies and policy development must be funded by respective African governments.

\subsection{Narratology of the Study}

A qualitative approach was found to be more appropriate in understanding how has change in quality of research results and recommendations as policy inputs, affected effectiveness of policy provisions that have been designed to improve forest and wildlife management in Tanzania? The preference given to qualitative approach over quantitative in this study was due to the fact that, quantification of policy effects in Tanzania has been difficult because of lack of reliable, consistent and comprehensive data in almost all sources of statistics (UNEP 2002).

In this study, interpretivism was chosen as the research philosophy. Additionally, a flexible research design was adopted and an interpretive case study was employed. Since the study was qualitative, semi-structured interviews and interactions were conducted. In establishing the sample size and choosing respondents and sampling technique, the sample size was 40 respondents and non-probability sampling technique was chosen, and technique used was purposive.

Data transcription was carried out by professional transcribers and later translated from Swahili to English by independent translators to ensure limited chance of subjectivity and bias in the study. Data transcribed and translated were subsequently entered into NVivo software where they were auto-coded and analysed until themes were identified. After these themes were identified, each theme was further analysed and interpreted by using analytical techniques of Content analysis and Narrative analysis.

The logic behind data interpretation in narrative analysis is to translate the stories of respondent's experiences into a narrative form. Narrative form is said to be produced, once a coherent story from data has been constructed. In short, through the use of narrative analysis, the author provides new and interpreted narrative which has a different message, embedded with unbiased personal opinion when being constructed (Segel and Heer 2010). 


\section{Policy Research and Effectiveness of Policy Provisions}

Policy research in Tanzania has some challenges, and among the major challenge is the quality of research results and recommendations issued. The quality of existing research results and recommendations need to be improved, given that much of the research studies conducted are short-term in nature, taking six to twelve months to complete and eventually producing short-term solutions to long-term problems.

In this case, there are no supply-driven research studies which would feed or contribute into policy making process. Instead, the types of research studies undertaken at the moment are demand-driven research studies. Usually, these demand-driven research studies are not as impactful because they offer short-term solutions to ingrained problems.

Hence, supply-driven research studies are critical for effective policy provisions. Supply-driven research studies usually have terms of references prepared by the researcher and not the client. This type of research tends to produce better research results and recommendations as the project duration is longer and provides a broader scope of the assignment to researcher as compared to demand-driven research studies which is the opposite. In demand-driven research, everything is determined by the client from project duration, scope etc. and tend to offer short term solutions.

Poor quality of research results and recommendations is an outcome of the fact that the Government has not invested enough in research studies and this situation is glaring in the budget books of research institutions and public universities. Most of the research funds come from development partners as such, research results and recommendations produced, cannot feed into domestic needs, rather they feed into the needs of development partners.

\subsection{Researchers and Policy Making}

The biggest challenge that researchers face, is when results and recommendations of a particular research differ from the expected results and recommendations of clients. This typically occurs when bureaucrats have preconceived ideas about a particular subject matter under investigation. In such circumstance, bureaucrats decide to react by disregarding the research results and recommendations and resort to their own views on how to deal with a particular policy problem. They end up doing this in spite of costs that had been incurred while soliciting the information through consultancy contracts given to researchers to conduct those studies.

Such situation tends to demotivate researchers as they are not certain whether the recommendations of their study would be accepted or rejected after submission of the final report. Sometimes, when research recommendations differ from the expectations of the bureaucrats, bureaucrats and political actors may choose to openly protest against the issued recommendations.

A case in point, is the continued protests from villagers led by local political actors over the decision to expand Ruaha National Park. The decision is based on research recommendations on the importance of removing people who encroached into the reserve and established settlements and others who reside within wildlife corridors (i.e. natural routes where wildlife animals usually pass) as a way of expanding Ruaha National Park. The local political actors have been at the forefront to prevent the expansion of Ruaha National Park into village areas such as Igomelo, Luhango, Nyeregete and Ikoga Mpya.

Moreover, a particular incident took place back in 2012, when the Ministry of Foreign Affairs, East Africa, Regional and International Co-operation (MFAEARIC) decided to put away the research recommendations on how to implement economic diplomacy. Until date, there has been no official response or feedback from the MFAEARIC to researchers who carried out that particular assignment. Hence, such a situation implies that political actors and bureaucrats are not ready to accept new input or ideas other than those of their own. It is evident that political actors and bureaucrats' way of handling research recommendations which differ from their own is among the setbacks of policy making in Tanzania, and this eventually undermines the value of policy research.

Another setback in policy research, one would argue, is the fact that, the Government has not sufficiently invested in research studies so as to improve the effectiveness of policy provisions. Instead, it is largely development partners that has been providing funds for supply-driven research studies. It is unfortunate that the Government has not fully realised what research studies could offer towards improving the policy provisions. For any research study to contribute effectively to policy making, three factors need to prevail: firstly, funds must be available to conduct impactful research projects; secondly, the capacity to carry out such impactful research projects in terms of human resource availability and their level of skills; and thirdly, the conducive research environment.

Research studies are public goods, as the access to information (i.e. scientific knowledge) is among the basic human rights (Willinsky 2006). Thus, if research output (i.e. results and recommendations) is for public consumption, it means that whoever provides it, should be financed in order to further improve the quality of research studies being offered to the public. Unfortunately, research institutes in Tanzania do not receive enough budget allocation from the Government. Eventually, most research institutes have developed their own business 
models in order to be able to operate.

Renowned research institutes such as Economic and Social Research Foundation (ESRF), Ifakara Health Institute (IHI) and Research on Poverty Alleviation (REPOA) have developed their own business model of operations in order to finance their research projects due to inadequate funding from the Government. Other research institutes have been compelled to work with the Government on commissioned projects (demand-driven research projects) just to generate some revenue for covering operational expenses, even if the assignment is expected to have minimal contribution to policy making.

\subsection{Stakeholders and Policy Making}

Normally, bureaucrats have shown preference for directly using recommendations from stakeholders as input into policy making process. Additionally, stakeholders' recommendations have been directly used as policy inputs without subjecting them to validity test. However, a systematic validation process could help to double check the quality of issued recommendations. This confirmation test helps to establish accuracy of a particular recommendation issued by a single or group of stakeholders before using it as a policy input.

The practice of using stakeholders' recommendations as a direct policy input has contributed to weak policy provisions. The practice has produced weak policy provisions due to lack of validity test of stakeholders' recommendations against any related assumption or principle of a particular academic theory. It is unfortunate that the Government has gone ahead to make stakeholders' recommendations a prerequisite for the approval of draft policy document by the Cabinet. This provision therefore means that stakeholders' input alone is sufficient to justify and develop a public policy in Tanzania.

The decision to undermine the role of research studies and elevate stakeholders' recommendations consciously or unconsciously in policy making has largely contributed in policy failures or disjunctions. This is particularly prevalent in forest and wildlife management as there has been an increase in deforestation, forest degradation, animal extinction, animal poaching, human-wildlife conflicts etc. The involvement of stakeholders' in providing recommendations as stated earlier, is usually at both pre-formulation stage and post-formulation stage of policy making process. This situation has persisted because bureaucrats have a misconception that stakeholders' recommendations mostly reveal important policy issues needed for developing or reviewing a particular policy.

Moreover, the decision to undermine the role of research studies and elevate stakeholders' recommendations is based on the use of Cabinet Guide to Document Preparation (CGDP) 2014 (RE). The CGDP is being used as an excuse by bureaucrats to ignore the role or contributions of research to policy making, on the grounds that, a list of research recommendations in policy formulation has not been defined in the CGDP. The CGDP 2014 (RE) provides guidelines for the approval of a public policy by the responsible authority, in this case, the cabinet of ministers. An example that illustrates this point was when the bureaucrats involved in the development and revision of both the forest policy and wildlife policy, were asked about the role of research, and they responded with a short statement that a list of research recommendations was not in the list of CGDP, which means it is not a prerequisite.

The experts, in this case researchers, are like eagles, they may look at stakeholders' recommendations with an eagle eye and correct their recommendations, rather than just take them at face value. It is true that stakeholders are the ones affected by policy outcomes. However, the issued recommendations which come from stakeholders must be thoroughly scrutinised.

\subsection{Research in Forest Management}

The Tanzania Forestry Research Institute (TAFORI) is a public organisation established by Act No. 5 of 1980. It operates under MNRT with the responsibility to conduct, coordinate, regulate and disseminate forestry research and related scientific information and technology in Tanzania. However, TAFORI has been bedevilled with problems of inadequate funding which hinder the organisation's ability to accomplish its objectives.

The problem of limited funding which TAFORI faces, is also shared by the Forest Division (FD) in Ministry of Natural Resources and Tourism (MNRT). The FD has been using other researchers to conduct short-term research through consultancy assignments, especially at the time of soliciting comments or recommendations from researchers. In many cases, these researchers conduct desk research and hold some meetings and workshops with stakeholders to gather their opinions on various issues which might be of importance to forest management at the time. The meetings and workshops held with stakeholders are considered to bring together key actors involved in forest management to obtain their views. However, stakeholders seem unmotivated to attend these meetings as they are not informed about the significance of such meetings. They do not see the direct effect of these meetings and workshops on their livelihood, as such, they would rather choose to engage in other personal, social or economic activities.

For example, FD contracted the University of Dar es salaam (UDSM) to carry out a study to understand, to what extent forest policy addressed the critical environmental issues in Tanzania. Similarly, the Sokoine University of Agriculture (SUA) and other prominent researchers were contracted to investigate various issues of critical importance in forest management. Currently, when conducting policy review, these reports from short term 
research studies are being used as input for revising the Forest Policy 1998. Those research reports are being synthesised and examined in totality in order to identify policy issues and subsequently formulate their respective policy statements. In that way, FD considers the applied approach of engaging consultants to research for a period of six to twelve months, to be enough for revising Forest Policy 1998.

\subsection{Research in Wildlife Management}

Tanzania Wildlife Research Institute (TAWIRI) is a public organisation originally named Serengeti Wildlife Research Institute (SWRI) by Act of Parliament No. 4 of 1980. It operates under the MNRT with the responsibility of conducting and coordinating wildlife research in Tanzania. The name change from SWRI to TAWIRI, took place in 1999.

Local research institutes like TAWIRI are beset with financial challenges due to limited funds from the Government. They usually have to depend on funds from development partners to finance their operations and in many cases the funds usually come with specific research aims. For example, development partners may release special funds for conducting research on understanding the behaviour of chimpanzees. However, such a study might not be the priority of the Government at that particular time.

The involvement of TAWIRI as a government research institute in wildlife management as well as the history of wildlife research as a whole in Tanzania started as far back as the 1950s. Long-term research flourished between 1960 and 1970 when many research studies were conducted by foreign researchers such as Jane Goodall and others. For a long period of time research in wildlife management has been dominated by foreign researchers and even after the establishment of SWRI in 1980 and TAWIRI in 1999, foreigners continue to dominate wildlife research in Tanzania. Moreover, many studies conducted by TAWIRI continue to depend on funds from development partners.

In the past ten years, there has been no impactful wildlife management research project funded by the Government. Instead, TAWIRI has been receiving funds to conduct short-term research studies targeted at solving short-term problems that exists in wildlife management. Additionally, TAWIRI has no independent research plan, and even if it did, the implementation of such a research plan would be affected by the fact that, TAWIRI does not have its own funds to support its research operations. The failure of TAWIRI to conduct long-term research studies has resulted into a situation whereby the Government is unable to fully understand what is happening in wildlife reserves and wildlife management as a whole in Tanzania.

The importance of conducting long-term research in wildlife management, is to be able to answer fundamental questions like how change in socio-economic development, or change in human population growth has affected wildlife management. These kinds of questions cannot be answered by short-term research studies. Long-term research approach would enable MNRT to know the policy issues that affect conservation efforts and observe the trend of policy issues at local as well as global scale before developing a proper management plan.

The Wildlife Division (WD) of MNRT usually conducts annual surveys on wildlife management in Tanzania, but in recent times annual surveys have not been conducted due to non-availability of funds. The importance of such surveys is to show the trend or direction of the entire conservation efforts, in terms of its achievements and challenges. These surveys are similar to an audit exercise carried out on the entire system of wildlife management to show areas that require attention and improvement. Failure to conduct such an exercise has resulted in a situation whereby many experts in wildlife management have been making unsubstantiated claims about critical issues such as climate change and to what extent climate change affects wildlife management, while failing to provide reliable and verifiable data in support of their arguments.

\section{Conclusion}

This paper has examined the way change in quality of research results and recommendations as policy inputs, has affected the effectiveness of policy provisions that have been designed to improve forest and wildlife management in Tanzania. It is revealed that the quality of research results and recommendations as policy inputs has not been improved due to lack of supply-driven research studies and eventually caused weak policy provisions as there has been an increase in human-wildlife conflicts, deforestation, forest degradation, animal extinction and poaching. Lack of investment in supply-driven research studies is largely attributed by the preference given to stakeholders' recommendations over research studies. The paper, therefore, concludes that government investment in long-term research studies is of critical importance in order to know and understand fundamental issues and what really is taking place in forest and wildlife reserves as well as forest and wildlife management as a whole.

\section{References}

Ajakaiye, O (2007) 'Levelling the Playing Field: Strengthening the role of African research in policy-making in Sub-Saharan Africa' in Ayuk, ET and Marouani, MA (eds), The Policy Paradox in Africa: Strengthening Links Between Economic Research and Policymaking, Africa World Press and International Development Research Centre, New Jersey and Ottawa, pp. 19-36 
Ayuk, ET and Marouani, MA (2007) 'An Emerging Continental Consensus' in Ayuk, ET and Marouani, MA (eds), The Policy Paradox in Africa: Strengthening Links between Economic Research and Policymaking, Africa World Press and International Development Research Centre, New Jersey and Ottawa, pp. 277 - 281

Babeiya, E (2011) Liberalisation and Public Policy-making in Tanzania: A cross Sector Experience, Elixir International Journal

Dollar, D, Svensson, J (2000) What Explains the Success or Failure of Structural Adjustment Programmes?, The Economic Journal, Volume 110 (466): pp. 894-917

ESRF, (2004) The role of ESRF in Policy Process in Tanzania, Economic and Social Research Foundation

Goodin, RE (1982) Political theory and Public policy, University of Chicago Press, Chicago and London

Hyden, G (2006) Between State and Community: Challenges to redesigning governance in Africa, Indiana University Bloomington

Igoe, J and Croucher, B (2007) Conservation, Commerce and Communities: The Story of Community-Based Wildlife Management Areas in Tanzania's Northern Tourist Circuit, Journal of Conservation and Society pp. $534-561$

Lokina, RB and Robinson, EJZ (2008) Determinants of Successful Participatory Forest Management in Tanzania, Environment for Development in Tanzania (EfDT), Department of Economics, University of Dar Es Salaam, Tanzania

Marshall, G (1998) A dictionary of sociology: Policy research, Oxford University Press

Matte, AZ (2007) Study on options for Pastoralists to secure their Livelihood: Current policy making processes in Tanzania, CORDS

Ndumbaro, L (1993) Policy Making in Tanzania: The Changing Power Centre, The University of Dar es salaam

Quattara, M, Sylla, K, Diallo, S and Quattara, Y (2007) 'The new social contract between economic research and decision makers: Lessons from Cote d'Ivoire' in Ayuk, ET and Marouani, MA (eds), The Policy Paradox in Africa: Strengthening Links between Economic Research and Policymaking, Africa World Press and International Development Research Centre, New Jersey and Ottawa, pp. 37-69

Schlimmer, S and Provini, O (2015) Politics and Policies in Tanzania: A Comparative Study of Higher Education and Land Policies, ICPP

Segel, E and Heer, J (2010) Narrative Visualisation: Telling Stories with Data, Stanford University, Stanford

Self, RJ (2011) Policy development and implementation in the Bretton Woods Institutions: A Consideration of the legality, human rights impact and effectiveness of their programs, International Journal of Arts and Sciences

Shivji, I (1986) Law, State and the Working Class in Tanzania, James Currey, London, Heinemann, Portsmouth N.H., and Tanzania Publishing House, Dar es salaam

Tordoff, W (1972) Political Roles in a New State: Tanzania's First Decade, Journal of African Affairs, Vol. 71 (285): pp. $367-470$

UNEP, (2002) Integrated Assessment of Trade Liberalisation and Trade - Related Policies: UNEP Country Projects - Round II; A synthesis report, United Nations, New York and Geneva

Willinsky, J (2006) Why Open Access to Research and Scholarship? Journal of Neuroscience, Vol. 26 (36): pp. 9078-9079

Young, J (2007) 'Bridging Research and Policy: The Research and Policy in Development (RAPID) Approach' in Ayuk, ET and Marouani, MA (eds), The Policy Paradox in Africa: Strengthening Links between Economic Research and Policymaking, Africa World Press and International Development Research Centre, New Jersey and Ottawa, pp. 71-91 